\title{
BENEFICIOS DE ASEGURAR ANTE EL IMSS A TRIPULACIONES DE EMBARCACIONES MENORES MEXICANAS, EN CASOS DE SINIESTROS MARÍTIMOS
}

BENEFITS OF INSURING MINOR MEXICAN SHIP'S CREWS

IN IMSS, IN CASE OF MARITIME NEGATIVE EVENTS

BÉNÉFICES D'ASSURER A L'IMSS LE PERSONNEL D'EMBARCATIONS MINEURES MEXICAINES, EN CAS D'INCIDENTS MARITIMES

Alejandro ROMERO REYES*

\section{NACIONALIDAD DE EMBARCACIONES Y LAS EMBARCACIONES DE NACIONALIDAD MEXICANA}

$\mathrm{D}$ e acuerdo con el artículo 92 de la Convención de la Naciones Unidas sobre el Derecho del Mar (Convemar) y los artículos 4o., 5o. y 6o. de la Convención sobre el Alta Mar de 1958, para que las embarcaciones puedan ejercer legalmente la navegación, deben contar con una nacionalidad. En términos del derecho internacional del mar se conoce como el principio de la "Ley del Pabellón".

La Ley del Pabellón, a la que algunos tratadistas del derecho internacional identifican con la nacionalidad, es el derecho que tiene un Estado para otorgar su nacionalidad a una embarcación dada. De conformidad con el derecho del mar, cualquier embarcación debe tener sólo una nacionalidad. ${ }^{1}$

Tradicionalmente se entiende por "nacionalidad” el vínculo jurídico-político que sujeta a una persona con un Estado. No obstante, algunos casos de excepción para gozar de una nacionalidad lo constituyen las embarcaciones

Abogado postulante en seguridad social(abogaromero@hotmail.com).

1 Vargas, Jorge A., Terminología sobre derecho del mar, México, Ceestem, 1979, p. 344.

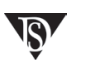


y las aeronaves. Estos bienes muebles, por normativa, deben poseer una nacionalidad.

En zonas donde ningún Estado ejerce jurisdicción, como alta mar o jurisdicción limitada; por ejemplo, la zona económica exclusiva, las embarcaciones se someten exclusivamente al Estado que les otorgó su nacionalidad, y salvo algunos supuestos de excepción, se someten a otras jurisdicciones; por ejemplo, cuando existan sospechas fundadas de que el buque se dedica a la piratería, al tráfico de esclavos, realiza transmisiones no autorizadas, no tenga nacionalidad, tenga la misma nacionalidad del buque de guerra que inspecciona, o se niegue a izar su pabellón, de acuerdo al artículo 110 de la Convemar y al artículo 22 de la Convención sobre el Alta Mar de 1958.

En conclusión, los Estados, en ejercicio de su soberanía, establecen normas internas para otorgar la nacionalidad a las embarcaciones que estarán autorizadas para ejercer la libertad de navegación. A su vez, con la nacionalidad otorgada por determinado Estado, éste puede ejercer jurisdicción preponderantemente exclusiva sobre aquella.

México reglamenta el otorgamiento de la nacionalidad de las embarcaciones en el Reglamento de la Ley de Navegación y otras disposiciones administrativas.

Para entender qué embarcaciones tienen derecho a gozar de la nacionalidad mexicana, de acuerdo al artículo 13 de la Ley de Navegación y Comercio Marítimos se establece que se considerarán como embarcaciones mexicanas a las siguientes:

I. Las abanderadas y matriculadas conforme a la ley.

II. Las que causen abandono en aguas de jurisdicción nacional.

III. Las decomisadas por las autoridades mexicanas.

IV. Las capturadas a enemigos y consideradas como buena presa.

V. Las embarcaciones que sean propiedad del Estado mexicano.

El primer supuesto, relativo a las abanderadas y matriculadas conforme a la ley, se refiere a aquellas embarcaciones que, a petición del propietario, armador o naviero de la embarcación, presentan la solicitud correspondiente ante la autoridad marítimo-portuaria, y en caso de cumplir con los requisitos, le otorgan la bandera y/o matrícula a la embarcación, y para comprobarlo le expiden un certificado de matrícula, en el cual consta la nacionalidad mexicana. El 
abanderamiento de las embarcaciones se otorga en términos del artículo 5o. del Reglamento de la Ley de Navegación. ${ }^{2}$

Respecto a la segunda hipótesis normativa, se configura el abandono de embarcación conforme a un procedimiento administrativo que lleva por finalidad la declaración de abandono; bajo esos términos se adjudica la embarcación a favor de la nación, de conformidad con el artículo 89 de la Ley de Navegación y Comercio Marítimos.

En cuanto a las embarcaciones decomisadas por autoridades mexicanas, implica que a través de un proceso un juez declare tal decomiso. Para que ese bien sea privado de la propiedad de un particular, se deben observar y respetar las garantías de legalidad, motivación y fundamentación. La situación jurídica de una embarcación cuando es detenida como instrumento del delito — por ejemplo, en el transporte ilícito de estupefacientes o personas inmigrantes irregulares-, tendrá la calidad de bien asegurado hasta que se resuelva la situación jurídica de los probables responsables.

La buena presa es una figura del derecho marítimo de guerra y se configura cuando dos países se encuentran en estado de guerra y se detiene a los barcos mercantes de los enemigos, e incluso a mercantes que apoyen a alguno de los beligerantes. Por la vocación pacifista de México, en tiempos recientes no existe un antecedente de este tipo. ${ }^{3}$

Finalmente, en cuanto a las embarcaciones propiedad del Estado mexicano, ${ }^{4}$ cabe aclarar que la administración pública, para el cumplimiento de sus atribuciones y funciones, en ocasiones requiere embarcaciones para fines de vigi-

2 El abanderamiento es el acto mediante el cual se impone la bandera mexicana a una embarcación o artefacto naval. Las embarcaciones y artefactos navales mayores deberán portar izada permanentemente la bandera nacional.

3 No obstante la vocación pacifista de México, en 1942, en el desarrollo de la Segunda Guerra Mundial, se incautaron trece embarcaciones mercantes con la bandera de Italia y de Alemania cuando el Estado mexicano declaró la guerra a las potencias del Eje: diez eran barcos propiedad de alemanes y tres eran de italianos. Algunos propietarios presentaron amparos, de los cuales derivó la siguiente tesis de jurisprudencia: "Barcos extranjeros. Incautación de". La Suprema Corte de Justicia de la Nación resolvió la legalidad de las incautaciones, aunque formalmente era ejercicio del derecho de angaria y buena presa.

4 Cabe aclarar que en el caso específico de las embarcaciones de la Secretaría de Marina, no le aplican las disposiciones de la marina mercante, lo que se refleja en el artículo 1o., párrafo segundo, de la Ley de Navegación y Comercio Marítimos, el cual establece: “...Quedan exceptuadas de las disposiciones de esta Ley las embarcaciones y artefactos navales de uso militar, pertenecientes a la Secretaría de Marina". 
lancia, inspección, mantenimiento de señalamiento marítimo en mar abierto, etcétera. Estas embarcaciones son consideradas como buques de Estado, destinados a fines no comerciales. Corresponde determinar la clasificación legal de las embarcaciones por su tamaño, para entender a qué embarcaciones se deben considerar menores.

\section{CLASIFICACIÓN LEGAL DE EMBARCACIONES POR SU DIMENSIÓN: MAYORES Y MENORES}

Existen amplias, diversas y respetables definiciones y clasificaciones de embarcaciones desde el punto de vista técnico y doctrinal. Sin embargo, para efectos de este trabajo se hará una delimitación desde el punto de vista legal, con base en tratados internacionales, leyes y reglamentos nacionales, para delimitar qué embarcaciones se consideran menores en el derecho mexicano.

Para determinar la clasificación de las embarcaciones por sus dimensiones en menores y mayores, previamente se debe comprender qué son unidades de arqueo bruto y la eslora de la embarcación, porque estos datos establecen el parámetro de las dimensiones de una embarcación.

La relevancia del arqueo bruto radica en que los buques mercantes están sujetos constantemente al pago de derechos de puerto, remolque, carenado, paso por canales, etcétera, y es evidente que éstos deben ser proporcionales a la capacidad comercial del buque. La manera más adecuada de expresar esta capacidad comercial es medir el volumen interno (sin contar ciertos espacios previstos en el reglamento de arqueo, y por ello llamados eximidos). ${ }^{5}$

En el ámbito regulatorio internacional, la definición de unidades de arqueo bruto la establece el artículo 2o., numeral 4, del Convenio Internacional sobre Arqueo, y se entiende como la expresión del tamaño total del buque.

Por otra parte, la definición legal de eslora, en el derecho mexicano, se encuentra en el artículo 2o., fracción VI, del Reglamento de Inspección de Seguridad Marítima, que establece: se entiende por eslora "el 96\% de la longitud total de una flotación situada a una distancia de la quilla igual al 85\% del puntal de trazado; o la longitud desde la cara proel de la roda, hasta el eje de la mecha del timón, en dicha flotación, si ésta fuera mayor".

\footnotetext{
5 Marpelli, Antonio, Elementos de arquitectura naval, 3a. ed., Argentina, Alsina, 1986, p. 6.
} 
En términos generales, la eslora del buque es la longitud de éste. El dato de unidades de arqueo bruto y la eslora invariablemente se encuentran en el certificado de matrícula. Como ya se mencionó, este documento jurídico hace prueba de la nacionalidad mexicana de una embarcación.

El legislador mexicano consideró tanto el arqueo bruto como la eslora para establecer una clasificación legal de las embarcaciones, lo que se refleja en el artículo 10 de la Ley de Navegación y Comercio Marítimos, el cual establece que las embarcaciones se clasifican por su uso y dimensiones en mayores y menores de la siguiente manera:

a) Buque o embarcación mayor o artefacto naval mayor: todo aquél de quinientas unidades de arqueo bruto o mayor que reúna las condiciones necesarias para navegar.

b) Buque o embarcación menor o artefacto naval: todo aquél de menos de quinientas unidades de arqueo bruto, o menos de quince metros de eslora, cuando no sea aplicable la medida por arqueo.

De lo anterior, se deduce que las embarcaciones hasta quinientas unidades de arqueo bruto legalmente se les considera menores. La relevancia de esta clasificación radica en que generalmente a este tipo de embarcaciones, en cuestiones de seguridad marítima, no resultan aplicables las disposiciones del Convenio Internacional sobre la Seguridad de la Vida Humana en el Mar de 1974, en su forma enmendada (de ahora en adelante Convenio SOLAS/74), el cual impone obligaciones de seguridad marítima generalmente a embarcaciones mayores de quinientas unidades de arqueo bruto y en algunos casos tratándose de embarcaciones de pasaje que sean mayores a trescientas unidades de arqueo bruto.

No obstante, para las embarcaciones menores mexicanas, el Reglamento de Inspección de Seguridad Marítima contiene disposiciones muy similares al SOLAS/74, entre cuyos objetivos implícitos se encuentra evitar accidentes, y por ende fallecimientos y lesiones a la gente de mar.

Las embarcaciones para navegar, además del certificado de matrícula y dependiendo del servicio a prestar, requieren otros certificados y documentos como se analizan a continuación. 


\section{CERTIFICADOS DE EMBARCACIONES MENORES PARA NAVEGAR Y EL SEGURO MARÍTIMO}

Las embarcaciones mexicanas para navegar, además de contar invariablemente con certificado de matrícula, deben cumplir con los certificados contemplados en el artículo 19 del Reglamento de Inspección de Seguridad Marítima o algunos de ellos, dependiendo del tipo de navegación que realicen y servicio destinado, como los siguientes:

- Certificado Nacional de Seguridad Marítima.

- Certificado Nacional de Dotación Marítima de Seguridad.

- Certificado Nacional de Arqueo Bruto.

- Certificado Nacional de Francobordo.

- Certificado Nacional de Seguridad para Embarcaciones de Pasaje.

- Certificado Nacional de Prevención de la Contaminación.

- Certificado Nacional de Estanqueidad para la Navegación a Remolque.

- Los demás que establezcan las disposiciones jurídicas aplicables.

Contar con los certificados vigentes presupone garantizar las condiciones de navegabilidad de la embarcación. Otra utilidad de los certificados es cumplir con los requisitos para la contratación del seguro marítimo, en sus diversos ramos, los que se explican a continuación.

En cuanto al seguro de las embarcaciones, de conformidad con el artículo 187 de la Ley de Navegación y Comercio Marítimos, los contratos de seguro marítimo podrán comprender todo interés asegurable legítimo y recaerán sobre:

- Las embarcaciones y los accesorios de éstas, cualquiera que sea el lugar en que se encuentren, incluso en construcción.

- Las mercancías, sus contenedores o cualquiera otra clase de bienes a bordo.

- El valor de la renta o el flete según sea el caso; los desembolsos en que incurra quien organice una expedición marítima, así como las comisiones por la comercialización de la carga.

— La responsabilidad civil. 
En términos del artículo 176 de la Ley de Navegación y Comercio Marítimos se establece que todas las embarcaciones que naveguen o artefactos navales que se encuentren en zonas marinas o en aguas interiores mexicanas, deberán contar con un seguro de protección e indemnización por responsabilidad civil. Esto en el argot marítimo se le conoce como "el seguro P\&I" o "seguro del pandi".

La cobertura del seguro de protección e indemnización por responsabilidad civil incluye el aseguramiento en caso de lesiones o fallecimiento de algún tripulante. Las condiciones de la cobertura se establecen en las reglas de los clubes de protección e indemnización. Éstos son sociedades mutualistas, de los cuales conviene enunciar a sus dos grandes especies de cobertura:

Protección. En general, la llamada "categoría protección" cubre las responsabilidades que se derivan de la propiedad del buque. Principalmente se cubre la responsabilidad derivada por muerte, accidentes y enfermedades de oficiales, tripulantes, pasajeros y todo sujeto embarcado; responsabilidades por abordaje no cubiertas por las pólizas de casco y máquina; daños a objetos físicos; cuarentena; remoción de gastos de naufragio, etcétera.

Indemnización. La segunda categoría, conocida como indemnity, cubre en general todas las responsabilidades que se deriven del empleo del buque, como consecuencia del transporte de su cargamento. Así, aquélla cubre las responsabilidades de los navieros relativas a la carga por falta de entrega, avería, excedentes, multas de inmigración, aduanas, etcétera. También se incluyen en esta categoría la contribución a la avería gruesa y el salvamento. ${ }^{6}$

En el caso de México, los seguros de protección e indemnización por responsabilidad civil sólo se pueden contratar con aseguradoras mexicanas de prima fija, quienes actúan como intermediarios de los clubes de protección e indemnización.

Cabe aclarar que las personas que pretendan asegurar embarcaciones mexicanas tienen prohibido hacerlo con empresas extranjeras, en términos del artículo 3o., fracción II, numeral 3, de la Ley General de Instituciones y Sociedades Mutualistas de Seguros; por ende, sólo lo pueden hacer con aseguradoras mexicanas. Consecuentemente, no es posible contratar directa-

6 Enríquez Rosas, José David, Transportes y seguros para el comercio internacional, México, Porrúa, 2002, p. 125. 
mente un seguro marítimo de responsabilidad civil con los clubes de protección e indemnización, además de que son sociedades mutualistas extranjeras.

Acertadamente, explica el doctor David Enríquez, las aseguradoras mexicanas son simples intermediarias en la colocación de las pólizas inglesas de diversos sindicatos de Lloyd's, por lo que no nos encontramos con auténticos contratos internacionales, en los que la compañía de seguros se limita únicamente a hacer el fronteo de la operación. ${ }^{7}$

\section{INTEGRACIÓN DE TRIPULACIÓN DE UNA EMBARCACIÓN MENOR}

Por disposición del artículo 32 de la Constitución Política de los Estados Unidos Mexicanos, las embarcaciones de bandera mexicana únicamente deben ser tripuladas por mexicanos por nacimiento.

Sin embargo, en ocasiones se embarcan técnicos extranjeros para realizar actividades de inspección o reparación de embarcaciones de nacionalidad mexicana. Estas personas para efectos administrativos no se consideran tripulantes; no obstante, para efectos laborales, en algunos casos se configuran relaciones de trabajo y en otros casos prestación de servicios profesionales, lo que resulta legal, siempre y cuando se solicite la autorización de embarque de técnico extranjero ante la capitanía de puerto correspondiente, en términos del artículo 25 de la Ley de Navegación y Comercio Marítimos.

Por otra parte, el artículo 27 de la ley en comento establece que las tripulaciones de embarcaciones deberán contar con un capitán o patrón, así como con los oficiales que corresponda, según se establezca en los términos de los tratados internacionales, de la Ley de Navegación y Comercio Marítimos y del Reglamento para la Formación y Capacitación de los Tripulantes de la Marina Mercante y para la Expedición de Títulos, Certificados, Libretas de Mar y de Identidad Marítima (de aquí en adelante Reglamento de Formación).

Cabe comentar que en el argot marítimo al personal técnico que realiza funciones de inspección o reparación, en ocasiones, es identificado como "supernumerarios". Para determinar el número de tripulantes para la operación de una embarcación se debe sujetar a un certificado nacional de dotación mínima de seguridad.

\footnotetext{
7 Ibidem, p. 134.
} 
Respecto a la dotación, el capitán y abogado, José Luis Gabaldón, menciona que aunque cada derecho nacional contendrá normalmente un concepto de dotación, puede decirse que, en términos generales, se entiende por tal el conjunto de todas las personas embarcadas en un buque necesarias para su dirección, maniobras y servicios. Dentro de la dotación es habitual distinguir entre el capitán, los oficiales y el resto del personal empleado a bordo, en virtud de un contrato de embarque (marineros y demás subalternos). Desde luego, no forman parte de la dotación ni los pasajeros ni otras personas que, por diversas razones, puedan ir a bordo (familiares, acompañantes, prácticos de puerto, polizones, etcétera). ${ }^{8}$

En el derecho mexicano se entiende como dotación al número total de tripulantes a bordo, y como dotación mínima de seguridad, al número mínimo de gente de mar competentes y experimentados necesarios para garantizar la seguridad de la embarcación, la tripulación, los pasajeros, la carga, los bienes y la protección del medio marino, de conformidad con el artículo 161, último párrafo, del Reglamento de Inspección y Seguridad Marítima.

Para acreditar la capacidad técnica de la gente de mar a nivel internacional, para los oficiales, y en algunos casos para los marineros, se aplica el Convenio Internacional sobre Normas de Formación, Titulación y Guardia para la Gente de Mar (por sus siglas en inglés STCW 78/95, enmendado en Manila, 2010, referenciado así de ahora en adelante).

A nivel nacional, para acreditar la capacidad en la operación de embarcaciones menores, los oficiales y los marineros deben obtener refrendo de título, libreta de mar, identidad marítima, certificado de competencia o certificado de competencia especial, según la categoría y la función a realizar, de acuerdo a las disposiciones del Convenio STCW 78/95, enmendado en Manila en 2010, y el Reglamento de Formación.

De acuerdo al Reglamento de Formación se establecen las categorías de marinería y los requisitos para obtener la documentación que acredita la idoneidad de las personas para pertenecer a la tripulación de una embarcación menor.

Los propietarios, los armadores, los navieros u operadores están obligados a que la tripulación acredite ante ellos su capacidad técnica o práctica. En caso de no comprobarlo, ellos pueden incurrir en una infracción adminis-

8 Gabaldón, José Luis, Curso de derecho marítimo internacional, España, Marcial Pons, 2012, p. 343. 
trativa sancionada por el artículo 328, fracción II, de la Ley de Navegación y Comercio Marítimos. Además, por configurarse una relación de trabajo, ellos tienen la obligación de inscribir a sus trabajadores ante el Instituto Mexicano del Seguro Social (IMSS).

El derecho que asiste a los trabajadores de mar de embarcaciones menores a contar con un seguro social tiene como base la relación de trabajo, por lo que se analizará la regulación del trabajo marítimo en México a continuación.

\section{ANÁLISIS DE LA REGULACIÓN DEL TRABAJO MARÍTIMO EN LA LEY FEDERAL DEL TRABAJO}

Para entender la relación de trabajo de la gente de mar en México se debe ubicar a las partes que intervienen en estos contratos. Toda relación de trabajo, en términos de la Ley Federal de Trabajo, requiere de la parte patronal y del trabajador, con las modificaciones a la mencionada ley publicadas en el Diario Oficial de la Federación del 30 de noviembre de 2012, donde se permite la contratación de los trabajadores a través de la figura del outsorcing, es decir, de intermediarios.

Sin embargo, la reforma mencionada a la Ley Federal de Trabajo dejó pasar la oportunidad para actualizar las normas del capítulo III, "Trabajadores de buques" (artículos 187 a 226), ya que algunos artículos resultan anacrónicos y otros ineficaces e imprácticos; por ejemplo, la clasificación de categorías de personal que ya no existe en los barcos, como los fogoneros. Otro caso es clarificar si las disposiciones también se aplican al personal de artefactos navales, como plataformas petroleras fijas o semisumergibles, y en la medida de lo posible adecuar las normas a disposiciones internacionales contempladas en el Convenio STCW 78/95, enmendado en Manila en 2010. No pasa por desapercibido la existencia del Convenio sobre Trabajo Marítimo de la OIT, que México no ha ratificado, aunque sería materia de otro trabajo.

En cuanto a los sujetos que intervienen en la relación de trabajo, la parte patronal en el trabajo de la gente de mar está representada por propietarios, navieros, armadores, fletadores, gestores navales u operadores de embarcaciones. En algunos casos, la contratación se realiza por agencias de colocación de gente de mar u outsorcing. En cuanto a la parte trabajadora, las categorías de la tripulación se deben ajustar al Convenio STCW 78/95 y a las enmiendas de 
Manila en 2010, así como al Reglamento de Formación. En estos ordenamientos se contempla que la máxima jerarquía corresponde al capitán o patrón ${ }^{9}$ de la embarcación, y bajo su mando tienen la responsabilidad y disciplina de los oficiales, los marineros, los motoristas, los maquinistas, los cocineros, etcétera.

La Ley Federal del Trabajo regula el trabajo marítimo en las disposiciones del capítulo III, “Trabajadores de los buques". Para entender cómo está regulado el trabajo de la gente de mar en el derecho positivo mexicano, a continuación se analiza el capítulo mencionado y se comentan algunos aspectos que en la práctica no se cumplen y otros que resultan anacrónicos o ineficaces.

De acuerdo al artículo 187 de la Ley Federal del Trabajo se establece que las disposiciones del capítulo III se aplican a cualquier clase de barco o embarcación que ostente bandera mexicana; sin embargo, se omite su aplicación respecto a los artefactos navales, como las plataformas petroleras, ya que en algunos casos estos artefactos son semisumergibles con capacidad para navegar y otras son fijas.

En cuanto al artículo 188 de la Ley Federal del Trabajo, se establece que están sujetos a las disposiciones del capítulo III: los capitanes; los oficiales de cubiertas y máquinas; los sobrecargos y los contadores; los radiotelegrafistas; los contramaestres; los dragadores; los marineros y el personal de cámara y cocina; los que sean considerados como trabajadores por las leyes y disposiciones sobre comunicaciones por agua, y, en general, todas las personas que desempeñen a bordo algún trabajo por cuenta del armador, naviero o fletador.

En esos términos se excluye a los ya mencionados supernumerarios; por ejemplo, ¿qué pasa con los electricistas que eventualmente reparan o proporcionan mantenimiento a los aparatos eléctricos de embarcaciones cuando éstos se encuentran en muelles o, incluso, en navegación, y no desempeñan un trabajo a bordo por cuenta del armador?, ¿se les puede considerar como gente de mar?

Aunque la norma citada anteriormente se limita a señalar como fuente de trabajo que las labores sean por cuenta del armador, naviero o fletador, es omisa respecto a otras figuras jurídicas de personas que explotan las embar-

9 A efecto de evitar interpretaciones incorrectas, en el contexto marítimo la connotación de patrón, embarcaciones menores, se refiere a marineros que se forman en la práctica y ascienden de categorías, lo cual acreditan con experiencia y cursos, mas no son los propietarios de la embarcación o de la fuente de trabajo. 
caciones; por ejemplo, los casos de operadores, subfletadores, comodatarios, etcétera. Cabe aclarar que en ocasiones, comercialmente, el armador no necesariamente es el propietario de la embarcación. En el derecho mercantil marítimo puede ocurrir que los armadores no sean los propietarios, por lo que en todo caso, en cuestiones de litigio laboral, procesalmente se debe demandar a la fuente de trabajo.

En términos del artículo 21 de la Ley de Navegación y Comercio Marítimos se presume que el propietario o copropietario de la embarcación son sus navieros o armadores. En caso de haber un operador, se deberá hacer la declaración de armador ante la autoridad marítima, por lo que se puede dar el caso de que una persona opere embarcaciones de otras. En caso de no hacer la declaración de armador, el propietario y el naviero responderán solidariamente de las obligaciones derivadas de la explotación de la embarcación, conforme a la disposición anteriormente citada.

En términos del artículo 189 de la Ley Federal de Trabajo, los trabajadores de los buques deberán tener la calidad de mexicanos por nacimiento, no adquirir otra nacionalidad y estar en pleno goce y ejercicio de sus derechos civiles y políticos, lo que resulta acorde con el artículo 32 constitucional y el artículo 25 de la Ley de Navegación y Comercio Marítimos; sin embargo, en la práctica se han presentado casos de embarcaciones de extraordinaria especialización para el apoyo de operaciones y trabajos de plataformas petroleras e instalaciones costa afuera, e inicialmente por cuestiones técnicas, éstas son operadas por personal extranjero, que debe capacitar al personal mexicano para no violar las disposiciones mexicanas; por ende, las embarcaciones o artefactos navales inicialmente no se abanderan como mexicanas. Dos formas de resolver jurídicamente ese hecho es obteniendo un permiso temporal conocido como "pasavante de navegación", o a través de la autorización de un técnico extranjero desde un punto de vista del derecho administrativo, aunque para efectos laborales al operador, sea nacional o extranjero, mientras tenga una relación de trabajo, se le debe considerar como un trabajador.

En el caso de las plataformas petroleras fijas, si se ubican en la zona económica exclusiva, es decir, más allá de las doce millas náuticas y hasta las doscientas millas náuticas, se someten a la jurisdicción del Estado mexicano, en términos del artículo 56, numeral 1 , inciso b, subinciso i, de la Convemar. Consecuentemente, aun cuando no estén matriculadas y abanderadas 
como mexicanas, el Estado mexicano puede ejercer jurisdicción, incluyendo los conflictos laborales, cuya competencia para dirimirlos es de jurisdicción federal, en términos del artículo 123, apartado A, fracción XXXI, subinciso b, numeral 3, de la Constitución Política de los Estados Unidos Mexicanos.

Además de las disposiciones administrativas en las que establecen responsabilidades, funciones y facultades al capitán o patrón de la embarcación, en términos de los artículos 27 y 28 de la Ley de Navegación y Comercio Marítimos, el artículo 190 de la Ley Federal del Trabajo les impone la obligación de considerarlos representantes del patrón (es decir, de la fuente de trabajo) respecto a los demás trabajadores.

De acuerdo al artículo 191 de la Ley Federal del Trabajo se prevé la prohibición del trabajo en buques a menores de quince años y el de menores de dieciocho en calidad de pañoleros o fogoneros. La categoría de fogonero es inexistente en la actualidad, tomando en cuenta que los barcos ya no se mueven con vapor y, por lo tanto, ya no necesitan calderas que deban ser abastecidas por trabajadores. En la actualidad, el funcionamiento de los motores de las embarcaciones ha transitado a máquinas de diesel y, más recientemente, se utilizan motogeneradores que abastecen a la máquina principal, por lo que resulta anacrónica esta disposición.

Por otra parte, el artículo 192 de la Ley Federal de Trabajo establece, en el primer párrafo, que no se considera relación de trabajo el convenio que celebren a bordo personas que se hayan introducido a él y que tengan por objeto devengar con servicios personales el importe de su pasaje. La disposición anterior no es clara en lo relativo a las personas que se hayan introducido a la embarcación y que pretendan laborar a bordo, caso diferente a la situación de los polizones, que son personas que subtefugiamente abordan una embarcación.

Aunque cabe aclarar que el fenómeno de los polizones ocurre con mayor incidencia en el tráfico de navegación de altura en embarcaciones mayores, no siendo común que acontezca en embarcaciones menores; sin embargo, de la interpretación del artículo citado se desprende que una persona puede abordar una embarcación de pasajeros y devengar con servicios personales su pasaje. En los buques de carga general (petroleros, portacontenedores, abastecedores, etcétera), legalmente, no se permite subir personas a bordo para prestar servicios personales.

Los únicos que están facultados para abordar embarcaciones son los oficiales, la marinería y, en su caso, los trabajadores que se dirigen a plataformas 
petroleras en las lanchas de pasaje para el servicio costa afuera. Por tanto, si ellos no cuentan con título, refrendo, documento de identidad marítima, libreta de mar, certificado de competencia especial o certificado de competencia para realizar una función a bordo de una embarcación o en la lista de tripulantes, administrativamente no es posible que puedan abordar el barco. Lo anterior de acuerdo al Convenio SOLAS, STCW 78/95 y enmiendas de Manila en 2010, o al Reglamento de Formación.

Por otra parte, en términos del párrafo segundo del artículo 192 de la Ley Federal de Trabajo se establece que tampoco se considera relación de trabajo el convenio celebrado para prestar servicios con los mexicanos que deban repatriarse a solicitud del cónsul respectivo, lo que resulta ineficaz, ya que en la actualidad la repatriación de mexicanos o extranjeros, generalmente, se hace vía aérea y no marítima, porque resulta oneroso e impráctico regresar a las personas que abordan subterfugiamente un barco vía marítima, pues las embarcaciones en ruta fija o servicio de línea irregular, en ocasiones, tardan en regresar al puerto donde pudo haber abordado el presunto infractor; además, la naviera, el armador, el fletador, etcétera, tendrían el riesgo de ser multados por violaciones a las leyes migratorias de los puertos de los Estados a donde previamente arriben, antes de regresar al destino donde haya abordado el polizón.

Las condiciones de trabajo de la gente mar deben constar por escrito; por ende, para evidenciar lo anterior, el artículo 192 de la Ley Federal de Trabajo dispone que un ejemplar de ese contrato debe quedar en poder de cada parte, y otro se remitirá a la capitanía de puerto o el cónsul más cercano. Esta situación difícilmente ocurre en la realidad, al menos en las embarcaciones menores.

Además, la obligación de remitir las condiciones de trabajo no es clara, porque no se refiere si se deben remitir a la capitanía de puerto de matrícula de la embarcación, al puerto donde se hayan enrolado los tripulantes o al puerto donde preponderantemente arribe la embarcación.

Para la contratación de la gente de mar en navegación de altura existe un contrato-tipo de la Federación Internacional de Trabajadores del Transporte (ITF), en donde se establecen las condiciones de trabajo de la gente de mar a nivel mundial, por lo que resulta ineficaz la norma analizada.

De acuerdo al artículo 193 de la Ley Federal de Trabajo, las personas que presten sus servicios a bordo exclusivamente por el tiempo que el buque se 
encuentre en puerto quedan sujetas a las disposiciones del capítulo III de la Ley Federal de Trabajo. Cabe preguntarse ¿sería el caso de los pilotos de puerto? De una interpretación lógica y sistemática no se desprende que así sea, porque el pilotaje consiste en un servicio portuario, en términos del artículo 44 de la Ley de Puertos. Los pilotos de puerto técnicamente son asesores para auxiliar a las embarcaciones que puedan arribar y atracar el barco a un puerto de manera segura.

Por otra parte, antes del 2002 cuando los barcos se encontraban surtos en puertos mexicanos, habían personas que abordaban para prestar servicios de lavandería, peluquería, etcétera; sin embargo, con la entrada en vigor del Capítulo XI-B del Convenio SOLAS/74 (dicho capítulo también conocido como Código PBIP), los recintos portuarios quedaron restringidos al acceso público y embarcar a personas ajenas al barco quedo prohibido.

Además, el Código Internacional de Gestión de la Seguridad Operacional del Buque y la Prevención de la Contaminación (de ahora en adelante Código IGS) es un ordenamiento cuyo objetivo es garantizar la seguridad marítima y que se eviten tanto lesiones personales o pérdidas de vidas humanas como los daños al ambiente. También este Código establece que las compañías, es decir, quien tenga la operación del barco, cuente con protocolos de seguridad para evitar actos ilícitos a bordo de la embarcación, por lo que prohíbe que personas ajenas al barco aborden la embarcación.

De acuerdo al artículo 194 de la Ley Federal del Trabajo, las condiciones de trabajo de la gente de mar deben constar por escrito, donde cada parte se quedará con un ejemplar y otro se remite a la capitanía de puerto o al cónsul mexicano, además a la Oficina de Inspección en el Trabajo del lugar donde se estipularon. Esta disposición es impráctica, debido a que las capitanías sólo tendrían conocimiento, pero no facultades para sancionar, y además se debe remitir a la Oficina de Inspección de Trabajo, quien sí tendría facultades para iniciar un procedimiento administrativo.

El artículo 195 de la Ley Federal de Trabajo establece que los requisitos mínimos del contrato de las tripulaciones deben incluir: lugar y fecha de celebración; nombre, nacionalidad, edad, sexo, estado civil y domicilio del trabajador y patrón; buque donde prestará sus servicios; si se celebra por tiempo determinado, indeterminado o por viaje; el servicio que deba prestarse; distribución de horas, salario, alojamiento y alimentos; periodo de vacaciones; de- 
rechos y obligaciones del trabajador; porcentaje por salvamento, y las demás estipulaciones que convengan las partes.

En la práctica, si un trabajador del mar exigiera esas condiciones previamente a su contratación en embarcaciones mexicanas menores, tal y como lo dispone la norma, con mucha probabilidad no sería contratado. En el caso de los trabajadores de embarcaciones de Pemex o sus subsidiarias, ellos se sujetan al contrato colectivo de trabajo y a los reglamentos internos de la paraestatal.

El artículo 196 de la Ley Federal del Trabajo establece que la relación de trabajo por viaje comprenderá el término contado desde el embarque del trabajador hasta concluir con la descarga en el puerto donde convenga. Si es por tiempo determinado o indeterminado, se fijará el puerto en que deba ser restituido y a falta de ello se tendrá por señalado el lugar donde se le tomó. En el caso de embarcaciones con ruta predeterminada es posible cumplir con la norma; sin embargo, si por causas de fallas técnicas o necesidades del trabajo la embarcación realiza arribadas imprevistas o forzosas a un puerto distinto, no será posible cumplir con la norma; cuando esto ocurre, el trabajador generalmente se regresa vía aérea o terrestre.

En términos del artículo 197 de la Ley Federal del Trabajo, para la prestación de servicios de trabajadores mexicanos en buques extranjeros se debe observar lo dispuesto en el artículo 28 de la Ley Federal del Trabajo, donde nuevamente se encuentra otra disposición que en la práctica no se aplica. Cuando algún oficial o marino mercante mexicano va a prestar sus servicios a un buque extranjero, generalmente las navieras extranjeras utilizan los ya mencionados contratos modelo de la ITF, reconocidos a nivel internacional.

De acuerdo al artículo 198 de la Ley Federal del Trabajo, cuando el buque se encuentre en el mar y la naturaleza del trabajo no permita el descanso semanal, se aplicará el artículo 73 Ley Federal de Trabajo, el cual dispone que los trabajadores no están obligados a prestar servicios en sus días de descanso. Si se quebranta esta disposición, el patrón pagará al trabajador, independientemente del salario que le corresponda por el descanso, un salario doble por el servicio prestado.

Por la naturaleza de la actividad que desarrollan las embarcaciones, en ocasiones hacen travesías por varios días, pero no significa que los trabajadores de mar se encuentren laborando las 24 horas, ya que existen guardias; no obstante, cuando bajan a tierra, les conceden los descansos respectivos. 
Los barcos, generalmente, se encuentran en el mar, salvo embarcaciones que se encuentran en astillero, dique seco o embarcaciones menores, como las lanchas de placer que son remolcadas, por lo que el citado artículo 198 debió decir "mientras las embarcaciones se encuentran navegando".

De conformidad con el artículo 199 de la Ley Federal del Trabajo, los trabajadores tienen derecho a un periodo mínimo de doce días laborables de vacaciones anuales pagadas, que se aumentarán en dos días laborables, hasta llegar a veinticuatro por cada año subsecuente de servicios. Con posterioridad se aumentará el periodo de vacaciones en dos días por cada cinco años de servicios. Las vacaciones deberán disfrutarse en tierra, pudiendo fraccionarse cuando lo exija la continuidad del trabajo.

Se debe recordar que éstas son las condiciones mínimas legales, aunque en la realidad hay casos en la industria petrolera costa afuera, como el trabajo en plataformas marítimas o embarcaciones, donde se enrolan a trabajar catorce por catorce o veintiocho por veintiocho.

De acuerdo al artículo 200 de la Ley Federal de Trabajo no es violatorio del principio de igualdad de salario la disposición que estipule salarios distintos para trabajo igual, si se presta en buques de diversas categorías. Esta disposición resulta acertada, ya que, por ejemplo, no es lo mismo el riesgo de trabajar en un barco remolcador que en un barco abastecedor. Además se deben considerar las categorías de los trabajadores de mar en la tripulación y sus funciones en el certificado de dotación.

En lo relativo al pago de los salarios de la gente de mar, el artículo 201 de la Ley Federal de Trabajo dispone que a elección de los trabajadores, los salarios podrán pagarse en el equivalente en moneda extranjera, al tipo de cambio que rija en la fecha en que cobren, cuando el buque se encuentre en puerto extranjero. En la práctica, el contrato-tipo ITF establece previamente entre la naviera y los trabajadores que la moneda de pago del salario, generalmente, será en dólares americanos, independientemente donde se encuentre el barco. Con las transferencias bancarias de dinero, vía depósito es la forma en que se hace el pago. En el caso de las embarcaciones menores, la regla general es que el pago a la tripulación se realiza en pesos mexicanos.

De acuerdo al artículo 202 de la Ley Federal de Trabajo, los trabajadores por viaje tienen derecho a un aumento proporcional de salarios en caso de prolongación o retado de aquél, y no podrán reducirse si se abrevia el viaje. 
En ocasiones, la operación del barco prolonga su estadía en un puerto, a esto se le conoce como demora por estadía, sobrestadía y contraestadía, por lo que, en términos del artículo citado, a los trabajadores les tendrían que pagar los días de retraso.

De conformidad con el artículo 203 de la Ley Federal del Trabajo, los salarios y las indemnizaciones de los trabajadores disfrutan de preferencia sobre otros adeudos, por lo que el propietario del buque es solidariamente responsable con el patrón de la embarcación, por los salarios e indemnizaciones de los trabajadores; en este sentido, cuando concurran créditos de trabajo procedentes de diferentes viajes, tendrá preferencia los del último. Esta disposición se relaciona con los privilegios marítimos que establece el artículo 91, fracción I, de la Ley de Navegación y Comercio Marítimos, que establece el derecho de los trabajadores de mar a ser preferido en el pago frente a otros acreedores.

De conformidad con el artículo 204 de la Ley Federal del Trabajo, la fuente de trabajo respecto a la gente de mar tiene las siguientes obligaciones especiales con relación a los trabajadores:

- Proporcionar a bordo alojamientos cómodos e higiénicos.

- Proporcionar alimentación sana, abundante y nutritiva a los trabajadores dedicados al servicio de altura y cabotaje y de dragado.

- Proporcionar alojamiento y alimentos cuando el buque sea llevado a puerto extranjero para reparaciones y sus condiciones no permitan la permanencia a bordo.

- Pagar los costos de la situación de fondos a los familiares de los trabajadores, cuando el buque se encuentre en el extranjero.

- Conceder tiempo a los trabajadores para ejercer el voto en elecciones populares, siempre que la seguridad del buque lo permita.

- Permitir a los trabajadores desempeñar comisiones del Estado o de su sindicato.

- Proporcionar alimentación y alojamiento, tratamiento médico y medicamentos en caso de enfermedades o cualquiera que sea su naturaleza.

- Llevar a bordo el personal y material de curación que establezcan las leyes y disposiciones sobre vías de comunicación.

- Repatriar o trasladar al lugar convenido a los trabajadores, salvo las causas de separación por causas no imputables al patrón. 
- Informar a la capitanía de puerto correspondiente, dentro de las veinticuatro horas de haber sido declarada la libre plática, de los accidentes de trabajo ocurrido a bordo. Si el buque llega a puerto extranjero, el informe se rendirá al cónsul mexicano o, en su defecto, al capitán del primer puerto nacional que toque.

En síntesis, sobre la obligación de proporcionar alimentos y alojamientos, es parte de la salud ocupacional o industrial a bordo de las embarcaciones. En cuanto al pago de salarios, en la actualidad se ha simplificado con el pago de nómina vía bancaria. Ejercer el voto cuando el barco se encuentra en operaciones se vuelve difícil, ya que por ese objetivo específico el trabajador puede bajar del barco cuando se encuentra en funciones, al igual que las comisiones del sindicato, salvo que ya tenga un puesto dentro de éste. En cuanto al tratamiento médico, éste se encuentra cubierto dentro de las pólizas del seguro de responsabilidad civil. El informe de los accidentes de trabajo ocurridos a bordo también se puede realizar en la vía administrativa mediante el acta de protesta, de acuerdo al artículo 181 de la Ley de Navegación y Comercio Marítimos, e incluso permite presentarla ante el cónsul mexicano del puerto extranjero correspondiente, porque además el cónsul mexicano en el extranjero es autoridad marítima, en términos del artículo 7o., fracción III, de la ley anteriormente citada.

Por otra parte, el artículo 205 de la Ley Federal del Trabajo establece que los trabajadores están obligados a respetar y realizar las instrucciones y prácticas determinadas a prevenir riesgos del mar, las que se efectuarán en los términos que determinen las leyes y disposiciones sobre comunicaciones por agua. Los capitanes y los oficiales obrarán en estos casos como representantes de la autoridad y no como representantes de los patrones. A lo anterior se le conoce en el argot marítimo como "zafarranchos". En términos del Código IGS se deben realizar estos simulacros para eventuales emergencias, como hundimientos, incendios, encallamientos de la embarcación, etcétera. Esta norma robustece la autoridad de capitanes y patrones a bordo de las embarcaciones, en términos del artículo 27 de la Ley de Navegación y Comercio Marítimos, al otorgarles facultades para que sus decisiones sean respetadas.

El artículo 206 de la Ley Federal de Trabajo establece la prohibición en los expendios de a bordo para proporcionar, sin permiso del capitán, bebidas 
embriagantes a los trabajadores, al igual que drogas y enervantes. La disposición anterior también viene a ser parte del Código IGS. Pero esto no aplica para pasajeros, como en el caso de barcos que ofrecen el servicio de pesca deportiva por varios días; por ejemplo, en los puertos del Golfo de California, quienes van en un plan de recreación y esparcimiento.

El artículo 207 de la Ley Federal de Trabajo establece que en el amarre temporal de un buque, autorizado por la junta de conciliación y arbitraje, no da por terminada la relación de trabajo, sino que sólo suspende sus efectos, hasta que el buque se encuentre en servicio. Las reparaciones a los buques en muelles no se consideran como amarre temporal. Cabe aclarar que para configurar el amarre temporal se debe solicitar un permiso ante la capitanía de puerto, quien lo debe autorizar, de acuerdo al artículo 87 de la Ley de Navegación y Comercio Marítimo.

Las causas especiales de rescisión de las relaciones de trabajo de la gente de mar se encuentran establecidas en el artículo 208 de la Ley Federal del Trabajo, a saber son:

- La falta de asistencia del trabajador a bordo a la hora convenida para la salida, o que presentándose, desembarque y no haga el viaje.

- Encontrarse el trabajador en estado de embriaguez en horas de servicio mientras el buque esté en puerto, al salir el buque o durante la navegación.

- Usar narcóticos o drogas enervantes durante su permanencia a bordo, sin prescripción médica. Al subir a bordo, el trabajador deberá poner el hecho en conocimiento del patrón y presentarle la prescripción suscrita por el médico.

- La insubordinación y la desobediencia a las órdenes del capitán del buque en su carácter de autoridad.

- La cancelación o la revocación definitiva de los certificados de aptitud o de las libretas de mar exigidos por las leyes y los reglamentos.

- La violación de las leyes en materia de importación o exportación de mercancías, en el desempeño de sus servicios.

- La ejecución, en el desempeño del trabajo por parte del trabajador, de cualquier acto, o la omisión intencional o negligencia, que pueda poner en peligro su seguridad o la de los demás trabajadores. 
La terminación de las relaciones de trabajo de la gente de mar, de acuerdo al artículo 209 de la Ley Federal del Trabajo, se debe sujetar a las normas siguientes:

- Cuando falten diez días o menos para su vencimiento y se pretenda hacer un nuevo viaje que exceda en duración a este término, podrán los trabajadores pedir la terminación de las relaciones de trabajo, dando aviso con tres días de anticipación al de la salida del buque.

- Las relaciones de trabajo no pueden darse por terminadas cuando el buque esté en el mar o cuando estando en un puerto se intente la terminación dentro de las veinticuatro horas anteriores a su salida.

- Cuando el buque esté en el extranjero, en lugares despoblados o en un puerto, siempre que en este último caso se exponga al buque a cualquier riesgo por mal tiempo u otras circunstancias.

- Cuando las relaciones de trabajo sean por tiempo indeterminado, el trabajador deberá dar aviso al armador, naviero o fletador con setenta y dos horas de anticipación.

- Cuando el buque se pierda por apresamiento o siniestro, se darán por terminadas las relaciones de trabajo, quedando obligado el armador, naviero o fletador a repatriar a los trabajadores y a cubrir el importe de los salarios hasta su restitución al puerto de destino o al que se haya señalado en el contrato, y el de las demás prestaciones a que tuvieran derecho.

- El cambio de nacionalidad de un buque mexicano es causa de terminación de las relaciones de trabajo.

Otro de los motivos de terminación de las relaciones de trabajo es por siniestro del buque, pero si convienen en efectuar trabajos encaminados a recuperar el buque, se les pagarán los salarios por los días que trabajen, incluido el salvamento marítimo.

Aunque conviene aclarar que en muchas ocasiones son empresas especializadas en salvamento las que realizan las operaciones de salvamento. Además, la autoridad marítima debe manifestar si existió salvamento; esto se debe reflejar en el dictamen que emite la autoridad marítima, en términos de los convenios internacionales y el artículo 185 de la Ley de Navegación y Comercio Marítimos. 
De acuerdo al artículo 211 de la Ley Federal del Trabajo, el reglamento interior de trabajo, depositado ante la junta, deberá registrarse en la capitanía de puerto. La disposición no menciona ante qué capitanía, si la del puerto de matrícula, la del puerto donde habitualmente realiza sus operaciones o ¿cuál?

De conformidad con el artículo 212 de la Ley Federal del Trabajo, corresponde a la Inspección del Trabajo vigilar el cumplimiento de las leyes y demás normas de trabajo, atendiendo a las leyes y disposiciones sobre comunicaciones por agua, cuando los buques estén en puerto.

El artículo 213 de la Ley Federal de Trabajo establece que en la navegación interior y fluvial se aplican las disposiciones del capítulo de trabajadores de los buques, pero con unas variantes, como la alimentación de los trabajadores por cuenta de la fuente de trabajo y el descanso en tierra.

Finaliza el capítulo III de la Ley Federal del Trabajo con el artículo 214, el cual establece que corresponde al Ejecutivo federal determinar la forma de sostener la casa del marino; por ejemplo, en algunos puertos a través de los despachos de salida solicitan una aportación para su mantenimiento.

\section{SINIESTROS MARÍTIMOS}

El riesgo, en términos generales, es la posibilidad de que acontezca un daño. Por otra parte, de acuerdo al Diccionario de la lengua española, en la connotación de un contrato de seguro, se define al siniestro como la concreción del riesgo cubierto en dicho contrato y que determina el nacimiento de la prestación del asegurador.

La Ley de Navegación y Comercio Marítimos no establece una definición de accidente o incidente marítimo. La única aproximación de descripción de siniestros o incidentes marítimos se establece en la lista del artículo 182 de la ley en comento, que establece:

- El abordaje de embarcaciones de cualquier tipo, o bien de hidroaviones amarrados o en posición de amarrar o de despegar.

- Las arribadas forzosas e imprevistas.

- El naufragio, el incendio, las varaduras o el encallamiento.

- La avería común.

- El acto o la omisión que genere contaminación marina. 
- El cambio obligado de ruta o puerto de destino, ocasionado por caso fortuito o fuerza mayor.

De manera didáctica, orientadora y complementaria al artículo 182 de la Ley de Navegación y Comercio Marítimos, se pueden añadir otros accidentes e incidentes marítimos de la siguiente manera:

\begin{tabular}{|l|l|}
\hline \multicolumn{1}{|c|}{ Accidente marítimo } & \multicolumn{1}{c|}{ Incidente marítimo } \\
\hline $\begin{array}{l}\text { Contacto con muelle, boya u } \\
\text { objeto fijo }\end{array}$ & Hombre al agua \\
\hline Avería simple & Recuperación de cadáveres \\
\hline & Evacuación médica de tripulantes pasajeros \\
\hline & Objetos flotantes a la deriva \\
\hline & Falla mecánica o estructural de la embarcación \\
\hline & Polizones \\
\hline
\end{tabular}

En algunas ocasiones, derivado de los accidentes e incidentes mencionados, resultan personas fallecidas o lesionadas, incluyendo tripulantes, lo que conlleva un accidente de trabajo.

Para determinar las causas en la investigación de siniestros marítimos se tienen que estudiar de raíz tres factores: acción u omisión, y condiciones meteorológicas. Las acciones u omisiones que influyen en los accidentes e incidentes marítimos pueden ocurrir por falta de mantenimiento de las embarcaciones; errores humanos; fatiga; ausencia cultural de prevención de accidentes, etcétera. En este sentido, uno o la combinación de varios factores pueden ocasionar lesiones, pérdidas de vidas humanas o daños materiales.

Otro factor causal a la contribución de los siniestros son las condiciones meteorológicas por fenómenos imprevistos e imprevisibles; por ejemplo, trombas marinas, tormentas tropicales, huracanes, etcétera.

Por lo anterior, contar con seguro marítimo con cobertura en sus diversas ramas, y además tener asegurada a las tripulaciones en un régimen de seguridad social, ayuda a aminorar las pérdidas económicas ante siniestros o accidentes marítimos, a los navieros, a los armadores, a los operadores, a los fletadores, etcétera. 


\section{BENEFICIOS DE ASEGURAR A LAS TRIPULACIONES \\ ANTE EL INSTITUTO MEXICANO DEL SEgURO SOCIAL}

La premisa de la seguridad social obligatoria en México implica que todo trabajador sujeto a una relación de trabajo debe estar asegurado en el régimen obligatorio ante el IMSS, por establecerlo normas de orden público e interés social, tal como está contemplado en los artículos 1o., 2o., 4o., 5o. y 12 de la Ley del Seguro Social.

Para la organización y administración del Seguro Social existe un organismo público descentralizado con personalidad jurídica y patrimonio propio, de integración operativa tripartita, en la que concurren los sectores público, social y privado, conocido como IMSS. Además, esta institución tiene la característica de ser un organismo fiscal autónomo.

Los regímenes de incorporación a la seguridad social ante el IMSS se dividen en voluntario y obligatorio. Se establece que serán objeto de aseguramiento al régimen obligatorio las personas que presten en forma eventual o permanente un servicio remunerado, personal y subordinado. Para el cumplimiento de esa disposición, la Ley del Seguro Social establece el régimen obligatorio en su artículo 12, fracción I.

De acuerdo al riesgo del tipo de trabajo se puede clasificar la actividad en el IMSS. El trabajo de la gente de mar está clasificado de acuerdo al Reglamento de la Ley del Seguro Social en materia de Afiliación, Clasificación de Empresas, Recaudación y Fiscalización. En el artículo 196 de este ordenamiento se clasifica el riesgo del trabajo de mar en el grupo 72, fracción 721 y 722.

El beneficio de asegurar a tripulantes, para el armador, naviero o propietario, consiste en:

- Queda relevado de toda responsabilidad por accidente de trabajo, incluyendo las que provengan de un siniestro o incidente marítimo.

- De acuerdo al Reglamento de la Ley de Navegación, si la tripulación cuenta con seguro social, se le excluye de responsabilidad al patrón de contar con seguro marítimo para la tripulación, con la consecuente disminución de la prima del seguro, en términos de los artículos 17 y 39 del Reglamento de Turismo Náutico, y 80 del Reglamento de la Ley de Navegación. 
Los beneficios para el tripulante son:

- Aseguramiento en caso de accidentes o riesgos de trabajo; en caso de invalidez, obtendrá una pensión por incapacidad.

- Aseguramiento para sus beneficiarios, en un indeseable caso de fallecimiento, pensión de viudez u orfandad.

- Contar con una pensión en el futuro.

El caso de los trabajadores de planta de barcos de Pemex es diferente, por su contrato colectivo de trabajo, donde gozan de un sistema de pensión y atención médica propios de la institución.

El hecho de que navieros, armadores, fletadores y operadores cuenten con un seguro de responsabilidad civil y tengan asegurados a los trabajadores no se contrapone ni configura un coaseguro o doble aseguramiento de un mismo riesgo, porque la naturaleza jurídica del seguro marítimo es el derecho mercantil, mientras que el aseguramiento del trabajador en una relación de trabajo su naturaleza jurídica corresponde al derecho de la seguridad social.

Cabe concluir que asegurar a las tripulaciones ante el IMSS, en caso de siniestros, representa beneficios tanto para el trabajador como patrón. Si bien es cierto que el marco jurídico de la Ley Federal de Trabajo no está actualizado en lo relativo al trabajo marítimo, la relación de trabajo se configura al momento de que existe subordinación entre naviero, armador, fletador, operador con los oficiales y la marinería, por lo que lejos de considerarlo oneroso, resulta un beneficio para todos.

\section{BIBLIOGRAFÍA}

ENRIQUEZ RosAS, José David, Transportes y seguros para el comercio internacional, México, Porrúa, 2002.

GABALDÓN, José Luis, Curso de derecho marítimo internacional, España, Marcial Pons, 2012.

MARPelLI, Antonio, Elementos de arquitectura naval, 3a. ed., Argentina, Librería y Editorial Alsina, 1986.

VARGAs, Jorge A., Terminología sobre derecho del mar, México, Ceestem, 1979. 


\section{Otras fuentes}

Constitución Política de los Estados Unidos Mexicanos.

Convención de las Naciones Unidas sobre el Derecho del Mar.

Convención sobre el Alta Mar de 1958.

Convenio Internacional sobre Normas de Formación, Titulación y Guardia para la Gente de Mar 78/95, enmiendas de Manila en 2010.

Convenio Internacional sobre la Seguridad de la Vida Humana en el Mar de 1974, en su forma enmendada.

Código Internacional de Gestión de la Seguridad Operacional del Buque y la Prevención de la Contaminación.

Ley del Seguro Social de 1997.

Ley Federal del Trabajo.

Ley de Navegación y Comercio Marítimos.

Reglamento de la Ley de Navegación.

Reglamento de Turismo Náutico.

Reglamento para la Formación y Capacitación de los Tripulantes de la Marina Mercante y para la Expedición de Títulos, Certificados, Libretas de Mar y de Identidad Marítima.

Reglamento de la Ley del Seguro Social en materia de Afiliación, Clasificación de Empresas, Recaudación y Fiscalización. 